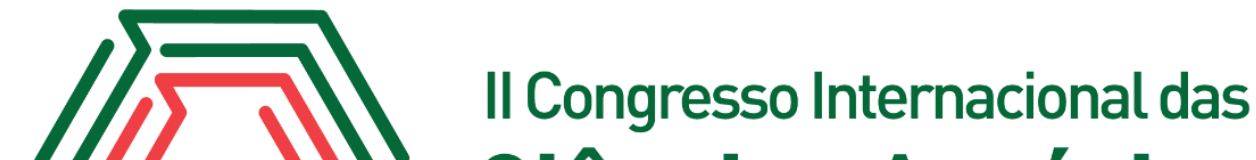 Ciências Agrárias COINTER - PDVAgro 2017
}

\section{COMPORTAMENTO DA ACIDEZ ATIVA E POTENCIAL DE UM LATOSSOLO AMARELO EM FUNÇÃO DE DIFERENTES CULTIVOS NO MUNICÍPIO DE ABAETETUBA-PA}

\author{
Apresentação: Pôster \\ Letícia Coelho Vaz Silva ${ }^{1}$; Eduarda Gonçalves Reis ${ }^{2}$; Kleve Freddy Ferreira Canteral ${ }^{3}$; \\ Manuella Almeida Raiol da Silva ${ }^{4}$; Mário Lopes da Silva Júnior ${ }^{5}$
}

\section{Introdução}

Os solos da Amazônia, com ênfase no Estado do Pará, são majoritariamente do tipo Latossolo Amarelo, com excessivo grau de intemperismo e consideráveis limitações nutricionais, carecendo de atenção às exigências das diferentes culturas, de forma que a ausência de manejo pode ter consequências na produtividade (SILVA, SILVA JUNIOR E MELO, 2006). Em solos agrícolas, essa avaliação também deve considerar fatores que aceleram a acidificação dos solos, como a utilização de insumos de reação ácida, a remoção de nutrientes básicos na fase de colheita e a lixiviação do nitrogênio em sua forma nítrica (CIOTTA et al., 2004).

Tendo em vista a influência da acidez do solo na produtividade, a acidez ativa $(\mathrm{pH})$ costuma ser amplamente utilizada como indicadora para recomendação de calagem no Brasil. A prática de correção de acidez e elevação do pH é importante para a disponibilidade de nutrientes essenciais às plantas, como os teores de $\mathrm{Ca}$ e $\mathrm{Mg}$, promovendo melhorias na absorção (CAIRES et al., 2002). Ademais, a acidez potencial $(\mathrm{H}+\mathrm{Al})$ é frequentemente incluída nas análises de fertilidade, devido às suas influências nas propriedades químicas do solo, entre as quais destaca-se a capacidade de troca catiônica (CTC) (ESCOSTEGUI e BISSANI, 1999).

Nesse contexto, o presente trabalho objetivou avaliar as condições de acidez ativa e potencial em solos do tipo Latossolo Amarelo distrófico sob cultivos em repouso e não manejados de açaí (Euterpe oleracea Mart.), de milho (Zea mays L.) e de pastagem, em uma fazenda no município de Abaetetuba-PA.

\footnotetext{
${ }^{1}$ Engenharia Ambiental e Energias Renováveis, Universidade Federal Rural da Amazônia, leticiacvaz@gmail.com

2 Engenharia Florestal, Universidade Federal Rural da Amazônia, eduardagreis@gmail.com

${ }^{3}$ Engenharia Ambiental e Energias Renováveis, Universidade Federal Rural da Amazônia, canteralkleve@gmail.com

${ }^{4}$ Engenharia Ambiental e Energias Renováveis, Universidade Federal Rural da Amazônia, manuellaalmeida39@gmail.com

${ }^{5}$ Engenheiro Agrônomo, Doutor e Professor do Instituto de Ciências Agrárias - ICA, Universidade Federal Rural da Amazônia, mario.silva@ufra.edu.br
} 


\section{Fundamentação Teórica}

Os Latossolos Amarelos são característicos de regiões úmidas tropicais e subtropicais, distinguidos como solos profundos, altamente intemperizados, com reduzidos valores de $\mathrm{pH}, \mathrm{CTC}$ e saturação por bases (SILVA, SILVA JUNIOR E MELO, 2006). Além disso, essas especificidades podem ocasionar teores elevados de Al trocável, tóxico ao desenvolvimento das plantas, de modo que o manejo da acidez é fundamental para o maior rendimento dos cultivos (CIOTTA et al, 2004).

A acidez ativa $(\mathrm{pH})$ é analisada através da determinação da atividade de íons $\mathrm{H}^{+}$na solução do solo. Esse parâmetro tem grande influência nos níveis de fertilidade, principalmente por ser um indicativo das condições gerais de disponibilidade de macro e micronutrientes, da solubilidade do alumínio em forma tóxica, ou ainda da atividade da microbiota, costumando variar ao longo do tempo em função do manejo e cultivo do solo (PREZOTTI e GUARÇONI, 2013).

Por outro lado, a acidez potencial $(\mathrm{H}+\mathrm{Al})$ representa os íons $\mathrm{H}^{+}$e $\mathrm{Al}^{3+}$ existentes nos colóides do solo. É utilizada como parâmetro para fertilidade, por influenciar o poder-tampão, a capacidade de troca catiônica (CTC) e o cálculo de necessidade de calcário (GAMA, PROCHNOW e GAMA, 2002). Pode-se conceituar a determinação de acidez potencial como a quantificação do teor de bases necessário para neutralizar determinado solo (KAMINSKI et al., 2002).

“A correção da acidez do solo é importante ao adequado desenvolvimento do milho, embora existam materiais genéticos mais tolerantes" (CAIRES et al. 2002). No caso das espécies forrageiras, as respostas à acidez são diferentes, pois algumas conseguem se estabelecer de forma modesta em solos ácidos (SANTANA et al., 2010). O açaí, por fim, pode ser facilmente encontrado em solos distróficos, como em áreas com predomínio de Latossolo Amarelo (CALZAVARA, 1972).

\section{Metodologia}

O experimento foi desenvolvido na Fazenda Bela Vista (154’30,64’S, 4853’18,54’O), situada em Abaetetuba, mesorregião nordeste paraense. O clima é do tipo Am segundo a classificação de Köppen, e os solos predominantes são Latossolos Amarelos distróficos (MEDEIROS, 2012). A área total é de 500ha, dentre os quais 498ha foram avaliados, sendo as áreas de interesse cultivos inutilizados e não manejados de açaí (Euterpe oleracea Mart.), de milho (Zea mays L.) e de pastagem.

O delineamento experimental foi inteiramente casualizado e seguiu esquema fatorial $3 \times 2 \times 4$, 
avaliando três cultivos, duas profundidades $(0-20 \mathrm{~cm}$ e $20-40 \mathrm{~cm})$, quatro repetições. Cada repetição corresponde uma amostra composta, advinda de 15 amostras simples, por profundidade. $\mathrm{O} \mathrm{pH}$ em água foi obtido pelo método potenciométrico, enquanto a acidez potencial $(\mathrm{H}+\mathrm{Al})$ foi determinada com extrator acetato de cálcio 0,5M, conforme metodologia recomendada (EMBRAPA, 1997).

Os dados foram submetidos à ANOVA e teste de Tukey no software ASSISTAT 7.6. Além disso, foram gerados mapas de distribuição do pH na Fazenda para as duas profundidades, através da técnica de interpolação do inverso do quadrado da distância, no programa ArcGIS 10.5.1.

\section{Resultados e Discussões}

Os resultados da análise de variância para as referidas variáveis estão dispostos na Tabela 1: Tabela 1: Análise de variância dos parâmetros de acidez ativa e potencial, na estatística de Tukey. Fonte própria.

\begin{tabular}{clllll}
\hline \multicolumn{1}{c}{ Parâmetro } & FV & GL & SQ & QM & F \\
\hline \multirow{2}{*}{ Acidez ativa $(\mathrm{pH})$} & Tratamentos & 5 & 0,26777 & 0,05355 & $1,4511^{\mathrm{ns}}$ \\
& Resíduos & 18 & 0,66432 & 0,03691 & \\
\cline { 2 - 6 } & Total & 23 & 0,9321 & & \\
\hline \multirow{2}{*}{$\begin{array}{c}\text { Acidez potencial } \\
(\text { H+Al) }\end{array}$} & FV & GL & SQ & $\mathbf{Q M}$ & $\mathbf{F}$ \\
\cline { 2 - 6 } & Resíduos & 5 & 10,56462 & 2,11292 & $4,9969 * *$ \\
\cline { 2 - 6 } & Total & 18 & 7,61117 & 0,42284 & \\
\hline
\end{tabular}

** significativo ao nível de $1 \%$ de probabilidade. * significativo ao nível de $5 \%$ de probabilidade. ns: não significativo ao nível de $5 \%$ de probabilidade.

Constata-se que a acidez ativa do solo não apresentou resultados estatisticamente significativos, indicando pouca influência dos tratamentos (cultivos e profundidades) no $\mathrm{pH}$. Quando comparado às demais propriedades químicas do solo, o $\mathrm{pH}$ costuma apresentar baixa variabilidade em função do espaço e profundidades (SILVA e CHAVES, 2001).

Em contrapartida, a acidez potencial $(\mathrm{H}+\mathrm{Al})$ apresentou médias estatisticamente diferentes para os tratamentos. Os cultivos de açaí $(20-40 \mathrm{~cm})$ e milho $(0-20 \mathrm{~cm}$ e $20-40 \mathrm{~cm})$ apresentaram maiores teores de acidez potencial (Tabela 2), quando comparados à pastagem. Esse comportamento pode ser resultante da maior presença de matéria orgânica (MO) acumulada nos sistemas de milho e açaí inutilizados, uma vez que a MO pode ser uma fonte relevante de acidez potencial nos solos tropicais (CARDOSO, 2011). 
Tabela 2: Médias de tratamento da Acidez potencial $(\mathrm{H}+\mathrm{Al})$, na estatística de Tukey. Fonte própria.

\begin{tabular}{lcc}
\hline Cultivo & Profundidade & Média \\
\hline Pastagem & $0-20$ & $3,7150 \mathrm{abc}$ \\
Pastagem & $20-40$ & $3,1350 \mathrm{c}$ \\
Açaí & $0-20$ & $3,3100 \mathrm{bc}$ \\
Açaí & $20-40$ & $4,6025 \mathrm{ab}$ \\
Milho & $0-20$ & $4,7850 \mathrm{a}$ \\
Milho & $20-40$ & $4,6000 \mathrm{ab}$
\end{tabular}

As médias seguidas pela mesma letra não diferem estatisticamente entre si ao nível de 5\% de probabilidade.

$\mathrm{Na}$ Figura 1, observa-se a pouca variabilidade da acidez ativa na área, em duas profundidades, com valores variando de 4,6 a 5,8, indicando solos ácidos. Em 0-20cm (Figura 1a), as faixas ocupam áreas semelhantes, enquanto em $20-40 \mathrm{~cm}$ observa-se menor homogenia entre as faixas e proeminência da faixa 4,89-5,16 (Figura 1b), demonstrando valores mais ácidos que na camada $0-20 \mathrm{~cm}$. Esse efeito pode ser decorrente da presença de restos culturais na superfície, promovendo decréscimo do teor de $\mathrm{Al}^{3+}$ e acréscimos nos valores de $\mathrm{pH}$ na camada $0-20 \mathrm{~cm}$, o que não ocorre nas camadas mais profundas (TEIXEIRA et al, 2003).

Figura 1: Variabilidade espacial da acidez ativa $(\mathrm{pH})$ na Fazenda Bela Vista, em a) 0-20cm b) 20-40cm. Fonte Própria.

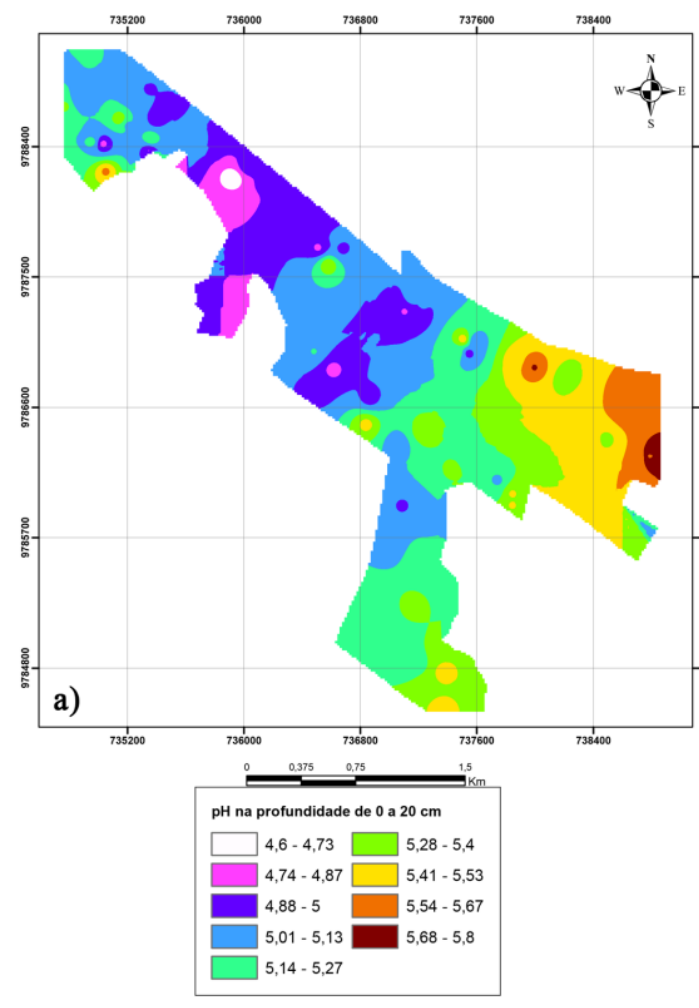

Datum Sirgas 2000 zona $22 \mathrm{~S}$

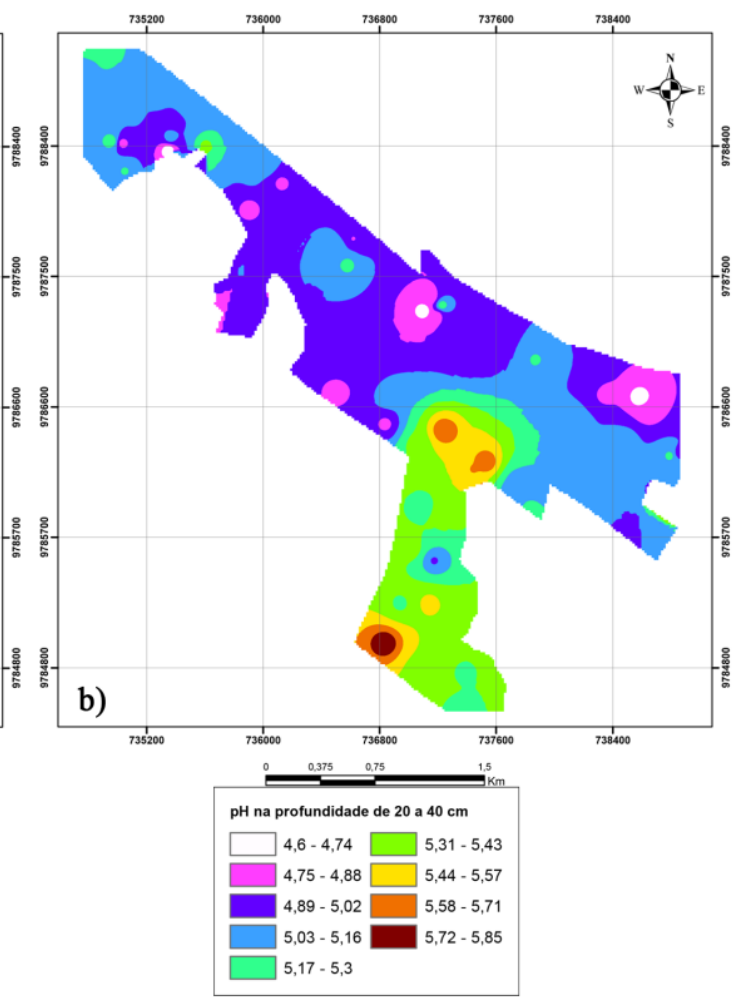

Datum Sirgas 2000 zona $22 \mathrm{~S}$ 


\section{Conclusões}

Não houve diferença estatística entre os tratamentos para a acidez ativa (pH). A acidez potencial $(\mathrm{H}+\mathrm{Al})$ teve maiores médias no cultivo de milho $(0-20 \mathrm{~cm}$ e $20-40 \mathrm{~cm})$ e açaí $(20-40 \mathrm{~cm})$. $\mathrm{O}$ pH expressou baixa variabilidade espacial $(4,6-5,8)$ e maiores valores na camada $20-40 \mathrm{~cm}$.

\section{Referências}

CAIRES, E. F. et al. Correção da acidez do solo, crescimento radicular e nutrição do milho de acordo com a calagem na superfície em sistema plantio direto. Revista Brasileira de Ciência do Solo, Viçosa, v. 26, n. 4, p.1011-1022, dez. 2002.

CALZAVARA, B.B.G. As possibilidades do açaizeiro no estuário amazônico. Belém: FCAP. 103p. 1972. (Boletim da Faculdade de Ciências Agrárias do Pará, 5)

CARDOSO, E. L. Qualidade química e física do solo sob vegetação arbórea nativa e pastagens no Pantanal Sul-Mato-Grossense. Revista Brasileira de Ciência do Solo, v. 35, n. 2, p.613-622, 2011.

CIOTTA, M. N. et al. Manejo da calagem e os componentes da acidez de Latossolo Bruno em plantio direto. Revista Brasileira de Ciência do Solo, Viçosa, v. 28, n. 2, p.317-326, abr. 2004

EMBRAPA. Empresa Brasileira de Pesquisa Agropecuária. Centro Nacional de Pesquisa de Solos. Manual de métodos de análise de solo. 2. ed. Rio de Janeiro: Embrapa Solos, 1997. 212 p.

ESCOSTEGUY, P. A. V.; BISSANI, C. A. Estimativa de H + AL pelo pH SMP em solos do Rio Grande do Sul e de Santa Catarina. Revista Brasileira de Ciência do Solo, v.23, n.1, 1999.

GAMA, M. A. P.; PROCHNOW, L. I.; GAMA, J. R. N. F. Estimativa da acidez potencial pelo método SMP em solos ocorrentes no nordeste Paraense. Revista Brasileira de Ciência do Solo, v. 26, n. 4, p.1093-1097, dez. 2002.

KAMINSKI, J. et al. Estimativa da acidez potencial em solos e sua implicação no cálculo da necessidade de calcário. Revista Brasileira de Ciência do Solo, v. 26, n. 4, p.1107-1113, dez. 2002

MEDEIROS, A. C. Obtenção do IQA para avaliação da qualidade da água em rios dos municípios de Abaetetuba e Barcarena (PA). 2012. 150 f. Dissertação (Mestrado) - Curso de Engenharia Civil, Instituto de Tecnologia, Universidade Federal do Pará, Belém, 2012.

PREZOTTI, L. C.; GUARÇONI M., A. Guia de interpretação de análise de solo e foliar. Vitória, ES: Incaper, 2013. 106 p.

SANTANA, G. S. et al. Produção e composição bromatológica da forragem do capim-mombaça (Panicum maximum Jacq.), submetidos a diferentes fontes e doses de corretivo de acidez. Semina: Ciências Agrárias, Londrina, v. 21, n. 1, p.241-246, jan./mar. 2010.

SILVA, G.R.; SILVA JUNIOR, M.L.; MELO, V.S. Efeitos de diferentes usos da terra sobre as características químicas de um latossolo amarelo do Estado do Pará. Acta Amazonica, v.36, n.2, 2006.

SILVA, P.C.M.; CHAVES, L.H.G. Avaliação e variabilidade espacial de fósforo, potássio e matéria orgânica em Alissolos. Revista Brasileira de Engenharia Agrícola e Ambiental, v.5, n.03, 2001.

TEIXEIRA, I. R. et al. Variação dos valores de pH e dos teores de carbono orgânico, cobre, 
manganês, zinco e ferro em profundidade em Argissolo Vermelho-Amarelo, sob diferentes sistemas de preparo de solo. Bragantia, v. 62, n. 1, p.119-126, 2003. 